\title{
GRAMSCI, EDUCADOR DAS CAMADAS POPULARES
}

\author{
RENÊ JOSÉ TRENTIN SILVEIRA ${ }^{1}$ \\ ORCID: https://orcid.org/0000-0003-4898-6588
}

\begin{abstract}
RESUMO: O objetivo deste artigo é realçar alguns dos aspectos teóricos da prática pedagógica de Antonio Gramsci, a fim de contribuir para o delineamento de sua pedagogia. Partindo sobretudo da análise de textos elaborados na fase da juventude, alguns ainda não publicados no Brasil, e de cartas do autor, pretende-se evidenciar seu radical compromisso político com a formação cultural e crítica das camadas populares e as formas pelas quais ele se traduziu em ações educativas concretas. Busca-se demonstrar, também, que tal compromisso esteve presente ao longo de toda a vida do autor, expressando-se nas diversas atividades que desenvolveu: como jornalista, como co-dirigente partidário, como fundador de escolas, como elaborador de programas de ensino e de materiais didáticos, como educador de adultos, atuando presencialmente ou a distância e em diferentes circunstâncias e espaços, inclusive na prisão. Evidentemente, o presente trabalho não esgota a discussão sobre a possibilidade de uma pedagogia gramsciana, tema que, pela sua complexidade e pela vastidão da obra do autor, permanece em aberto.
\end{abstract}

Palavras-chave: Antonio Gramsci, Educação popular, Hegemonia e educação, Marxismo e educação.

\section{GRAMSCI, EDUCATOR OF THE POPULAR CLASSES}

\begin{abstract}
The aim of this paper is to highlight some of the theoretical aspects of Antonio Gramsci's pedagogical practice in order to contribute to the delineation of his pedagogy. Starting from the analysis of texts written during his youth, some of them not yet published in Brazil, and from the author's letters, we intend to show his radical political commitment to the cultural and critical formation of the popular classes and the ways in which this translated into concrete educational actions. We also try to demonstrate that such commitment was present throughout the author's life, expressed in the several activities he developed: as a journalist, party co-director, founder of schools, elaborator of teaching programs and didactic materials, adult educator, acting in person or at a distance and in different circumstances and spaces, including prison. Obviously, the present work does not exhaust the discussion on the possibility of a Gramscian pedagogy, a topic which, due to its complexity and the vastness of the author's work, remains open.
\end{abstract}

Keywords: Antonio Gramsci, Popular education, Hegemony and education, Marxism and education.

\footnotetext{
${ }^{1}$ Universidade Estadual de Campinas (UNICAMP). Campinas, SP, Brasil. <rene@unicamp.br>
} Educação em Revista|Belo Horizonte|v.37|e20049|2021 


\section{GRAMSCI, EDUCADOR DE LAS CAMADAS POPULARES}

RESÚMEN: El objetivo de este artículo es realzar algunos de los aspectos teóricos de la práctica pedagógica de Antonio Gramsci, con el objetivo de contribuir para el delineamiento de su pedagogía. Partiendo sobre todo del análisis de textos escritos en la fase juvenil y de algunas cartas del autor, se pretende evidenciar su radical compromiso político con la formación cultural y crítica de las camadas populares y las formas por las cuales se tradujo en acciones educativas concretas. Se busca demostrar, también, que tal compromiso estuvo presente a lo largo de toda la vida del autor, expresándose en las diversas actividades que desarrolló: como periodista, codirigente partidario, como fundador de escuelas, como elaborador de planes de enseñanza y de materiales didácticos, como educador de adultos, actuando presencialmente o a distancia y en distintas circunstancias y espacios, incluso en la cárcel. Evidentemente, el presente trabajo no agota la discusión sobre la posibilidad de una pedagogía gramsciana, tema que, por su complejidad y por la vastedad de la obra del autor, permanece en abierto.

Palabras clave: Antonio Gramsci, Educación popular, Hegemonía y educación, Marxismo y educación. 


\section{INTRODUÇÃO}

O problema da educação, tanto no sentido escolar quanto no sentido mais amplo, de formação cultural e política da classe trabalhadora, ocupa lugar de destaque nas preocupações de Gramsci. Ao longo de seu percurso intelectual, intimamente entrelaçado em sua militância política, forjaram-se conceitos, princípios didáticos e concepções que, aos poucos, vão constituindo, embora de modo assistemático, uma pedagogia voltada para a formação crítica das camadas populares. ${ }^{2}$

Dialeticamente, tal pedagogia resulta dos desafios concretos postos por sua prática politicopedagógica: seja como jornalista, que educa pelas matérias que escreve; como organizador e codirigente de partido e de escolas; como elaborador de programas de ensino e de materiais didáticos; ou seja, ainda, como educador de adultos com níveis distintos de escolaridade, atuando presencialmente ou a distância e em diferentes circunstâncias e espaços, inclusive na prisão.

Evidentemente, este texto não esgota a discussão sobre a possibilidade de uma pedagogia gramsciana, tema que, pela sua complexidade e pela vastidão da obra do autor, permanece em aberto. O objetivo aqui proposto é, partindo sobretudo da análise de textos elaborados na fase da juventude, alguns ainda não publicados no Brasil, e de cartas do autor, evidenciar o radical compromisso político de Gramsci com a formação das camadas populares, expresso em sua práxis educativa, e realçar alguns dos aspectos teóricos dessa práxis que poderiam caracterizar sua pedagogia.

\section{AS PRIMEIRAS EXPERIÊNCIAS ESCOLARES}

O interesse de Gramsci pela educação data de suas primeiras experiências escolares, como demonstra seu excelente desempenho na escola elementar, a qual concluiu com nota máxima em todas as matérias (D’ORSI, 2018, p. 42). Além disso, muito precocemente percebeu a importância maior dessa instituição para os pobres do que para os ricos. Seu trabalho final, datado de 16 de julho de 1903, quando ele tinha, portanto, 12 anos de idade, versou sobre o seguinte tema: "se um seu colega abastado e muito inteligente revelasse a você a intenção de abandonar os estudos, o que você lhe responderia?" (Idem). Eis a resposta do garoto:

\footnotetext{
Você diz que não retomará os estudos porque ficou entediado. Como, você que é tão inteligente, que, graças a Deus, não lhe falta o necessário, vai abandonar os estudos? Você me diz para fazer o mesmo, porque é muito melhor correr pelos campos, ir aos bailes e às reuniões públicas, em vez de trancar-se por quatro horas em uma sala, com um professor que sempre nos manda estudar porque senão permaneceremos uns cabeças ocas. Mas eu, caro amigo, não poderei jamais abandonar os estudos porque eles são a minha única esperança de viver honradamente quando for adulto; porque, como você sabe, a minha família não é rica nem de bens nem de sorte.

Quantos rapazes pobres te invejam, eles que teriam vontade de estudar, mas a quem Deus não deu o necessário, não só para estudar, mas também, muitas vezes, nem para matar a fome.

Eu os vejo da minha janela, com que olhos veem os rapazes que passam com a bolsa a tiracolo, eles que só podem ir à escola noturna.

Você diz que é rico, que não precisará dos estudos para viver, mas lembre-se do provérbio: ‘O ócio é o pai dos vícios’. Quem não estuda na juventude se arrependerá amargamente na velhice. Volte aos estudos, caro Giovanni, e encontrará todos os bens possíveis (D’ORSI, 2018, p. 42 -
} 43). ${ }^{3}$

\footnotetext{
${ }^{2}$ A noção de "formação crítica" ou de "educação crítica" em Gramsci requer abordagem mais aprofundada. Por ora, podese dizer que inclui a defesa de uma educação integral, que equilibre formação profissional e formação geral (humanística, científica, filosófica e artística - a escola unitária) e que forme o jovem das camadas populares "como pessoa capaz de pensar, de estudar, de dirigir ou de controlar quem dirige" (GRAMSCI, 2006, C 12, \$2, p. 49). Sobre a escola unitária, ver o Carderno 12, da obra Cadernos do Cárcere (GRAMSCI, 2006).

3 Tradução nossa.
} 
Aos 11 anos, porém, Gramsci viu-se forçado a abandonar os estudos por certo período, para trabalhar e ajudar no sustento da família, que, àquela altura, enfrentava dificuldades financeiras (MAESTRI; CANDREVA, 2001). Tal fato fez nascer no menino um sentimento de revolta contra aquela situação que lhe parecia injusta. Afinal, por que ele, com notas tão boas, era privado de estudar, enquanto os filhos dos ricos prosseguiam, independentemente do rendimento que obtivessem? Em carta enviada de Viena, em 6 de março de 1928, à esposa Giulia, relembra:

O que me salvou de me tornar completamente um pano engomado? $\mathrm{O}$ instinto de rebelião, que desde menino era dirigido contra os ricos, porque não podia estudar, eu que havia tirado nota dez em todas as matérias da escola elementar, enquanto estudavam os filhos do açougueiro, do farmacêutico, do negociante de tecidos (GRAMSCI, 1994, p. 58). ${ }^{4}$

Esse sentimento da injustiça, experimentado na própria pele, e a indignação dele decorrente, estão na origem de sua crítica posterior, sobretudo nos Cadernos, ao caráter classista e oligárquico da escola.

\section{JORNALISTA EDUCADOR}

Gramsci concluiu a escola elementar e o Liceu em Ales, na Sardenha e, graças a uma bolsa de estudos, ingressou na Universidade em 1911, em Turim, no curso de Letras. A adaptação à nova realidade não foi fácil, tanto pelo choque cultural vivido por um jovem de vida simples, recém-chegado à cidade grande e à mais industrializada do país, quanto por suas precárias condições de subsistência e de saúde. De fato, a referida bolsa mal dava para pagar o aluguel. ${ }^{5}$ Movido em parte por essas razões e, também, por seu engajamento político no Partido Socialista Italiano (PSI), abandonou a faculdade para se dedicar mais intensamente à militância jornalística, principalmente a partir de 1915. Passou então a colaborar com os jornais Il Grido del Popolo e Avanti!, ambos vinculados ao PSI. Em 1917, escreveu integralmente e publicou, a partir da orientação da Federaz̧ione Giovanile Socialista Italiana, o jornal La Cittá Futura, de único número, especialmente dedicado à formação política e cultural dos jovens (MUSSI; BIANCHI, 2017). Em 1919, juntamente com seus colegas de universidade e de militância Palmiro Togliatti, Umberto Terracini e Angelo Tasca, fundou o jornal semanário L'Ordine Nuovo, cujo subtítulo era Resenha semanal de cultura socialista. O primeiro número saiu em 1 de maio com a seguinte palavra de ordem estampada na capa: "Instruí-vos porque precisamos da vossa inteligência. Agitai-vos, porque precisamos do vosso entusiasmo. Organizai-vos, porque carecemos de toda a vossa força".

Até sua prisão pelo governo fascista de Mussolini, em 1926, Gramsci havia escrito cerca de 1.700 artigos (MORAES, 2014), sobre os mais variados temas. O lema do L'Ordine Nuovo, aliado ao volume e à intensidade de sua atividade jornalística, dá a medida da importância que ele atribuía à formação política e cultural da classe trabalhadora, a quem esses jornais se dirigiam preferencialmente.

Mas como falar ao trabalhador de modo a atingir esse objetivo? Que linguagem e estilo adotar? Como lembra Paolo Nosella (1992, p. 28), esse problema foi enfrentado por Gramsci quando ainda escrevia no Il Grido del Popolo. Recusava-se a simplificar exageradamente a linguagem para evitar infantilizar seu público e converter o discurso político em catecismo doutrinário. Agir dessa forma, dizia, "não seria facilitar; seria fraudar, como faz o vendedor de vinho que vende água colorida em lugar de vinho Barolo ou de lambrusco" (GRAMSCI apud NOSELLA, 1992, p. 28). ${ }^{6}$ Para ele, os periódicos socialistas deveriam se adaptar "ao nível médio da clientela regional à qual se dirigem", mas atribuindo à escrita um tom "um pouco acima dessa média", a fim de "estimular o progresso intelectual" e a consolidação de uma "visão crítica da história e do mundo onde vive e luta" (Idem). E ele ainda advertia:

\footnotetext{
4 Tradução nossa.

${ }^{5}$ Conferir Nosella (2017, p. 14-15) e Gramsci (2005a, p. 190).

${ }^{6}$ Nosella cita o artigo "Cultura e lotta di classe", publicado no Il Grido del Popolo, em 25 de maio de 1918. Conferir Gramsci (2012, p. 269-272).
} 
A classe dirigente faz o mesmo [...] E nós deveríamos ficar eternamente às Geórgicas, ${ }^{7}$ ao socialismo agreste e bucólico? Deveríamos sempre, com insistência monótona, repetir a cartilha, porque há sempre alguém que nem a cartilha conhece? (GRAMSCI apud NOSELLA, 1992, p. 29).

E o que dizer aos trabalhadores? Que conteúdos culturais oferecer a eles? Em uma crônica do L’Ordine Nuovo, de 23 agosto de 1919, Gramsci nos dá uma ideia do tipo de formação que o jornal recém-criado pretendia proporcionar ao seu público. Nesse texto, expressa a sua desconfiança da escola burguesa, por deixar de ensinar aos operários o mesmo conjunto de saberes a que tinham acesso as elites econômicas. Em decorrência dessa desigualdade educacional, os trabalhadores, nos quais a luta de classes havia forjado um "senso novo de dignidade e de liberdade", ao se depararem com "os cantos dos poetas" ou com as obras dos "artistas e dos pensadores", passavam a se questionar, lamentando: "por que a escola não ensinou essas coisas também a nós?". Afinal, também eles desejavam e tinham direito a uma "escola completa", que lhes pusesse em contato com "todos os ramos do saber humano" (GRAMSCI, 1955, p. 119). ${ }^{8}$

Gramsci sabia que, a rigor, uma escola dessa natureza para a classe trabalhadora só seria viável no socialismo, quando, então, ela seria uma "necessidade prática" e, ao mesmo tempo, uma "exigência ideal". Contudo, até lá, já que não se poderia esperar muito da escola controlada pela burguesia, era preciso realizar a tarefa educativa das massas populares "por outras vias, livremente, através de associações espontâneas de homens animados do desejo comum de melhorarem-se a si mesmos". Pergunta-se, então: "por que um jornal não poderia se tornar o centro de um desses grupos?". Se o Estado burguês, preocupado unicamente em "acumular riquezas para os particulares", havia deixado cair a "tocha da ciência" e a "lâmpada sagrada da vida", caberia agora aos coordenadores do L'Ordine Nuovo, isto é, aos intelectuais comprometidos com as camadas subalternizadas, levantar do chão essa tocha e "fazê-la brilhar com uma nova luz" (GRAMSCI, 1955, p. 119-120). ${ }^{9}$

Nota-se, assim, já nessa fase jornalística, seu compromisso efetivo com o progresso intelectual de massa, expresso tanto na linguagem escolhida para se dirigir aos trabalhadores quanto no conteúdo a ser a eles apresentado. Recusa-se a se contentar com uma educação aligeirada, facilitada, fragmentada, parcial para os trabalhadores. Nada de cartilhas simplificadoras, doutrinárias e doutrinadoras. Nada de água colorida, nem mesmo de vinho barato, mas sim do que há de melhor: vinho Barolo! Cultura! ${ }^{10}$

Mas o que Gramsci entende por cultura? Em "Socialismo e cultura” (GRAMSCI, 2012), publicado no Il Grido del Popolo, em 29 de janeiro de 1916, ele critica a concepção usual que a considera como "saber enciclopédico" e segundo a qual o ser humano seria como um recipiente a ser preenchido com informações brutas e desconexas que ele deve "encaixotar em seu cérebro" para a elas recorrer quando necessário. Para ele, essa noção de cultura é prejudicial ao proletariado, pois serve para "criar deslocados", pessoas que se creem superiores ao resto da humanidade, apenas porque acumularam certa quantidade de dados na memória e que fazem disso uma barreira entre elas e as demais (Idem, 2016, p. 105). Ele diz:

O estudantezinho que sabe um pouco de latim e de história, o advogadozinho que conseguiu tirar um diploma chinfrim devido à indolência e à complacência dos professores, acreditarão ser diferentes e superiores até mesmo 'ao melhor operário especializado que executa na vida uma

\footnotetext{
${ }^{7}$ Segundo Pio (2017, p. 137), “As Geórgicas (37-30 a. C.) são um poema [de Virgílio] sobre a vida rural e as diversas atividades agrícolas".

8 Tradução nossa.

9 Pouco tempo mais tarde, ainda em 1919, em um artigo intitulado “A escola é uma instituição séria?”, publicado no Avantil, Gramsci defenderá enfaticamente a escola e afirmará fazê-lo em nome da classe trabalhadora (GRAMSCI, 1968, p. 101).

10 O Barolo, produzido na região do Piemonte, está entre os melhores vinhos da Itália e do mundo. A escolha dele na metáfora usada por Gramsci, portanto, não deve ter sido aleatória. Antes, sugere que a luta política pela emancipação dos subalternizados supõe assegurar a eles uma educação integral, com acesso à cultura mais elaborada, erudita, que os capacite não apenas para compreender científica e criticamente a sociedade e seu funcionamento, mas também para "pensar", "estudar", "dirigir" e "controlar quem dirige” (GRAMSCI, 2006, C 12, §2, p. 49).
} 
tarefa bem mais minuciosa e indispensável e que, na sua atividade, vale cem vezes mais que aqueles outros dois valem nas suas (GRAMSCI, 2012, p. 143). ${ }^{11}$

Esse “intelectualismo pernóstico e incolor", na realidade, não é cultura nem inteligência, mas sim "pedantismo", contra o qual se deve reagir. E o que seria, então, a cultura?

É organização, disciplina do próprio eu interior, é tomada de posse da própria personalidade, é conquista de uma consciência superior, pela qual se consegue compreender o próprio valor histórico, a própria função na vida, os próprios direitos e os próprios deveres (GRAMSCI, 2012, p. 143-144).

Contudo, isso não é algo que ocorra por "evolução espontânea", nem por força de algum fatalismo ou de uma hora para outra. Antes, supõe uma ação educativa intencional, planejada e de longo prazo, que capacite para uma "reflexão inteligente" sobre o porquê de certos fatos e sobre os meios para convertê-los em símbolo de rebelião. Com efeito, diz Gramsci (2012, p. 144): "toda revolução foi precedida de um intenso trabalho de crítica, de penetração cultural" que preparou o caminho para as transformações estruturais que se sucederam. Foi o caso, por exemplo, da Revolução Francesa, cujo caminho foi aberto pelo Iluminismo:

As baionetas dos exércitos de Napoleão encontravam o caminho já aplainado por um exército invisível de livros, de opúsculos, que eram disseminados a partir de Paris desde a primeira metade do século XVIII e que tinham preparado homens e instituições para a renovação necessária (GRAMSCI, 2012, p. 144).

Ora, o que valeu para a Revolução Francesa vale também para o socialismo. É preciso um amplo e contínuo trabalho educativo de base, que prepare o caminho para a transformação social, ao mesmo tempo em que se faz avançar a organização política das massas. Parece estarmos diante do processo de gestação da teoria da hegemonia e da concepção da educação como instrumento para sua construção em favor das classes populares.

Esse trabalho educativo e a reflexão inteligente por ele propiciada permitem empreender a crítica da civilização capitalista e chegar a uma "consciência unitária do proletariado". Este é o novo sentido atribuído por Gramsci ao adágio socrático "conhece-te a ti mesmo": significa "ser si mesmo", "ser dono de si mesmo", diferenciar-se, "distinguir-se", deixar o "caos", "ser um elemento da ordem, mas da própria ordem e da própria disciplina" (GRAMSCI, 2012, p. 145). E isso pressupõe, também, o conhecimento dos outros - por exemplo, da burguesia - e da sua história, ao longo da qual esses outros se tornaram o que são e criaram a civilização que agora o proletariado deseja substituir. Pressupõe, ainda, conhecer as leis da natureza e do espírito e "tudo aprender sem perder de vista o escopo último que é o de conhecer melhor a si mesmo através dos outros e os outros através de si mesmo" (Ibidem, p. 146).

A cultura, portanto, se não é saber ornamental, também não é ausência de saber! Segundo Manacorda (1990, p. 22-23), no texto Socialismo e cultura, Gramsci critica e busca superar duas tendências opostas de sua época: de um lado, a "concepção enciclopédica e paternalista do saber como uma sólida bagagem de noções a serem transmitidas a título de benevolência" e, de outro lado, o "desprezo à cultura em nome do fato, a subestimação do aspecto teórico em nome do aspecto prático". No lugar desses extremos, ele propõe uma "ação que seja cultural" e uma "cultura que seja ativa". Em uma palavra, a cultura como práxis.

Essa noção de cultura o leva também a rejeitar "qualquer forma de instrução popular amesquinhada pelo assistencialismo cultural” (NOSELLA, 1992, p. 21), como podemos observar em sua crítica à Universidade Popular de Turim.

As universidades populares destinavam-se a um público específico: adultos que não conseguiram seguir os estudos nas escolas regulares e na idade convencional. Havia uma dessas instituições em Turim, que Gramsci analisa no artigo "A Universidade Popular", publicado no Avanti!,

\footnotetext{
11 Tradução de Regina Célia da Silva, do Centro de Estudos de Línguas (CEL), da Universidade de Campinas (Unicamp).
} Educação em Revista|Belo Horizonte|v.37|e20049|2021 
em 29 de dezembro de 1916 (GRAMSCI, 2012, p. 176-179). ${ }^{12}$ Segundo ele, os dirigentes dessa instituição não se preocupavam em buscar a melhor maneira de aproximar os alunos do "mundo do conhecimento". Em vez disso, tratavam-nos como se tivessem a mesma idade e a mesma formação dos estudantes regulares das universidades públicas e, por isso, ofereciam-lhes algo "similar", porém, "inferior". Isso convertia a Universidade Popular em uma espécie de "renovação da escola jesuítica, na qual o conhecimento era apresentado como algo definitivo, apoditicamente indiscutível". Ora, diz Gramsci: "isso não se faz nem mesmo nas universidades públicas" (Ibidem, p. 177-178).

Havia, portanto, um sério problema administrativo e metodológico, que tornava essa universidade uma "chama fria" e que fazia com que ela não fosse "nem universidade, nem popular" (Ibidem, p. 177). O que movia seus diretores era um "leve e inexpressivo espírito de beneficência", isto é, uma inspiração assistencialista, filantrópica, populista e não um "desejo vivo e fecundo de contribuir para a elevação espiritual da multidão através do ensino" (idem). A exemplo das instituições de caridade, distribuíam "cestas de suprimentos que enchem o estômago", que talvez até "provoquem indigestão", mas que "não deixam uma marca, não têm uma continuidade de vida nova, de vida diferente" (idem). Em suma, não transformavam a vida dos beneficiários.

A esse "método enciclopédico estanque", Gramsci contrapõe, segundo Nosella (1992, p. 22), o "método historicista", o qual consiste em refazer, com e para os alunos, o caminho percorrido pela humanidade para chegar ao conhecimento com os seus "esforços", os seus "erros" e as suas "vitórias". Afinal, "uma verdade é fecunda apenas quando houve um esforço para se conquistá-la". Ela "não existe em si e por si", mas é uma "conquista do espírito" (GRAMSCI, 2012, p. 178). ${ }^{13}$

É preciso, portanto, reproduzir nos estudantes "aquele estado de ansiedade por que passou o estudioso" e que o levou a alcançar a verdade que buscava (Idem). Daí a importância de o professor ensinar também a "história de sua matéria" (Idem). Afinal, permitir que os alunos refaçam o percurso que conduz ao conhecimento é algo "muito mais educativo que a exposição esquemática desse mesmo conhecimento". Isso porque:

Forma o estudioso, dá ao seu espírito a elasticidade da dúvida metódica, que faz do amador o homem sério, que purifica a curiosidade, comumente entendida, e a torna estímulo saudável e fecundo para um conhecimento cada vez maior e perfeito (GRAMSCI, 2012, p. 178).

Esse é o caminho que os professores devem percorrer, sobretudo com os estudantes das universidades populares, aos quais, justamente, falta até mesmo o contato mais elementar com a pesquisa. Praticado dessa maneira, conclui Gramsci, o ensino se torna, de fato, "um ato de libertação" (GRAMSCI, 2012, p. 178).

\section{EDUCADOR - PRESENCIAL E A DISTÂNCIA - DE JOVENS E ADULTOS NO INTERIOR DO PARTIDO}

Para Gramsci, o partido político revolucionário, autenticamente empenhado na emancipação das camadas subalternizadas, precisa atuar também na formação cultural delas. Essa ação deve se dirigir, em primeiro lugar, aos seus próprios quadros, tanto às lideranças quanto aos demais militantes.

Com esse objetivo, ele e os seus companheiros do L'Ordine Nuovo criaram, em 1919, a Escola de Cultura e Propaganda Socialista, voltada para o público interno ao Partido. O programa da escola foi primeiramente publicado no L'Ordine Nuovo, em 29 de novembro daquele ano, com o título "Il programma della scuola di propaganda". Era dividido em quatro eixos temáticos, com os seguintes assuntos e seus respectivos professores:

\footnotetext{
12 Tradução de Regina Célia da Silva (CEL/Unicamp).

${ }^{13}$ No Caderno 12, ele dirá: “descobrir por si mesmo uma verdade, sem sugestões e ajudas exteriores, é criação, mesmo que a verdade seja velha, e demonstra a posse do método; indica que, de qualquer modo, entrou-se na fase da maturidade intelectual, na qual se podem descobrir verdades novas" (GRAMSCI, 2006, v. 2, C 12, \$1, p. 40).
} 


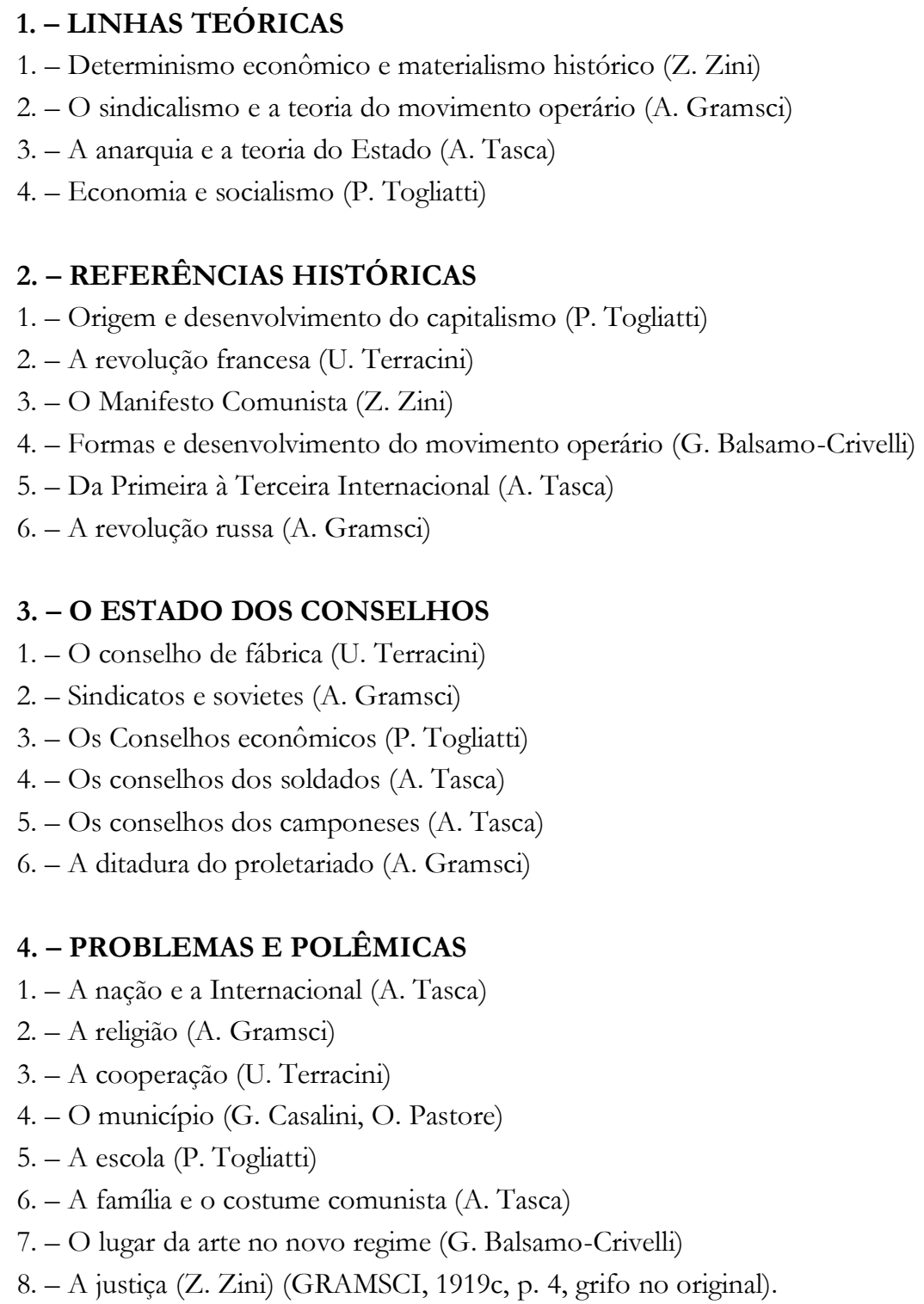

Como vemos, Gramsci atuava não apenas na concepção e na direção do curso, mas também como professor. Quanto à metodologia de ensino, recomendava-se que cada assunto fosse "tratado de modo didático, procurando-se fixar a atenção dos alunos em alguns conceitos e no nexo lógico do raciocínio". Para auxiliar nesse trabalho, deveriam ser elaboradas apostilas com um "resumo esquemático de cada lição, contendo não mais do que quatro páginas impressas" (GRAMSCI, 1919c, p. 4). Aos mais interessados e que dispusessem de mais tempo, seria indicada uma bibliografia complementar para aprofundamento do estudo de temas específicos.

O programa previa, ainda, que os alunos se exercitassem na discussão de assuntos previamente combinados com o professor. Todos, porém, deveriam demonstrar que estudaram os temas gerais, o que incluía, por exemplo, o "Manifesto Comunista", de Marx e Engels, cujos conceitos fundamentais esperava-se que soubessem "expor claramente", e o opúsculo de Trotsky: "Da revolução de outubro à paz de Brest-Litowski", "no qual é exposto com eficácia o processo histórico da revolução russa, o caminho seguido pelas forças proletárias para alcançar a conquista efetiva do poder político" (GRAMSCI, 1919c, p. 4). Esse programa poderia ser modificado de acordo com as necessidades e complementado com palestras de companheiros que não figuravam na lista de professores.

Finalmente, os dirigentes da escola pretendiam fornecer, não apenas aos alunos, mas também aos outros companheiros, "um guia prático para a formação e a integração de sua cultura". Para tanto, 
seriam elaboradas listas de livros, "agrupados de acordo com os assuntos e a maior ou menor dificuldade", que formariam ou completariam as bibliotecas dos Círculos educativos dos operários (GRAMSCI, 1919c, p. 4).

$\mathrm{Na}$ semana seguinte ao início do funcionamento da escola, tendo sido ministradas as primeiras aulas, Gramsci já registrara, em uma crônica no L'Ordine Nuovo (GRAMSCI, 1919a, p. 1), e até com alguma surpresa, sua satisfação com os bons resultados obtidos. Surpresa porque, a princípio, alguns duvidavam que, encontrando-se apenas "uma ou duas vezes por semana" e "cansados do próprio trabalho", os alunos estariam animados para estudar (Idem). No entanto, o que viram foi algo diverso: "aglomerados, espremidos um no outro, em bancos desconfortáveis e em um espaço apertado, aqueles alunos incomuns", a maioria "não mais jovem e, portanto, fora da idade em que aprender é algo simples e natural" e ainda "fatigados pela jornada de trabalho na oficina ou no escritório" e, mesmo assim, acompanhando as aulas com atenção. Isso mostra que, entre educadores e educandos, "se estabeleceu uma corrente viva de inteligência e simpatia"14. Em suma, eram alunos "com vontade de se tornarem melhores", "de conquistar consciência", de "se tornarem capazes" de pensar e donos do próprio pensamento e da própria ação, "artífices diretos" da história de sua própria classe (Idem).

Em uma segunda crônica, de 27 de dezembro daquele mesmo ano (GRAMSCI, 1919b, p. 1), Gramsci dá mais detalhes do sucesso da escola. Informa, por exemplo, que depois da "publicidade nacional" que a ela fora dada pelo L'Avanguardia (Idem, 1919d, p. 4), a direção passou a receber inúmeras cartas de companheiros que moravam distante de Turim, "jovens e operários", lamentando não poderem frequentar as aulas e solicitando que lhes fossem enviadas as apostilas usadas nos cursos e as listas de livros indicados. Por sua vez, os dirigentes se sentiam na "obrigação moral de atendê-los", o que pretendiam fazer publicando o material da escola no próprio L'Ordine Nuovo, juntamente com um resumo esquemático dos conceitos apresentados nas aulas teóricas (Idem, 1919b, p. 1). Assim, para os alunos, esse material seria "um guia de estudo" e "um roteiro para revisar e retomar sinteticamente o caminho percorrido". Já para os de longe, seria "um teste", um "incentivo à emulação", para que tentassem fazer o mesmo, ainda que a distância.

O sentimento de obrigação moral de atender à solicitação dos companheiros que não podiam frequentar presencialmente a escola mostra o compromisso pedagógico e político de Gramsci e dos seus companheiros do L'Ordine Nuovo com a formação de todos os trabalhadores.

Sobre o desempenho dos estudantes nos cursos, a maioria demonstrava "querer trabalhar seriamente". Os professores liam e discutiam os escritos dos alunos e "não poucos dentre esses" revelavam-se "notáveis pela precisão do pensamento e da expressão", inclusive nas "apresentações orais e questões específicas" (GRAMSCI, 1919b, p. 1). Isso nos dá uma ideia das atividades pedagógicas desenvolvidas: aulas teóricas, provavelmente expositivas, discussões orais, produção de textos, sintetizando conceitos e debates, leitura cuidadosa da produção dos alunos para fins de avaliação.

Poucos anos mais tarde, em um editorial do L'Ordine Nuovo, de 1 de abril de 1925, intitulado “A escola de Partido", Gramsci (1973, p. 114) ${ }^{15}$ recordaria “o sucesso e a repercussão" positiva dessa escola, embora reconhecesse que foram menores do que se esperava e tivesse sido curta a sua duração: na verdade, "nem mesmo o tempo necessário para que fosse desenvolvido o programa traçado no início" $($ Idem $){ }^{16}$

Sob o fascismo, com o cerceamento da liberdade de expressão e de reunião e o avanço da repressão, a escola de partido não poderia mais existir como antes. O próprio Gramsci nos dá um panorama daquela situação de "terror branco":

Os operários mais ativos são perseguidos, são controlados em todos os seus movimentos, em todas as suas leituras; as bibliotecas operárias foram incendiadas ou desmanteladas; as grandes organizações e as grandes ações de massa não existem mais e não podem atuar. Os militantes não participam, de modo algum, ou participam apenas em uma medida limitadíssima, das discussões e do debate de ideias (GRAMSCI, 1978, p. 51).

\footnotetext{
14 Sobre a concepção gramsciana da relação professor-aluno, ver Silveira (2018).

15 Tradução nossa.

16 A esse respeito, ver também Nosella (1992, p. 56-57). 
Agora era preciso buscar outras formas de realizar a formação dos próprios quadros. Uma das alternativas encontradas foi a educação a distância, por correspondência. Gramsci se refere a essa experiência no artigo "O Programa de L'Ordine Nuovo", publicado nesse mesmo jornal, em 1 de abril de 1924. ${ }^{17}$ O curso então concebido deveria se tornar "a primeira fase de um movimento pela criação de pequenas escolas de partido", visando a preparar "organizadores e propagandistas bolchevistas, não maximalistas que tenham, portanto, cérebro além de pulmões e garganta" (GRAMSCI, 1973, p. 75). ${ }^{18}$

Para Gramsci, Maximalistas eram aqueles que, mesmo dentro do partido comunista, incorporavam uma "concepção fatalista e mecanicista da doutrina de Marx" (GRAMSCI, 2012, p. 544) e para os quais a vitória final do proletariado seria inevitável, fruto do movimento histórico concebido abstrata e mecanicamente. ${ }^{19}$ Gramsci contrapõe a esse fatalismo metafísico o método dialético que aprendera de Lenin:

O companheiro Lenin nos ensinou que, para vencer nosso inimigo de classe, que é poderoso, que dispõe de muitos meios e reservas à sua disposição, devemos aproveitar cada rachadura em sua frente e devemos utilizar todo aliado possível, ainda que incerto, oscilante e provisório. Ele nos ensinou que, na guerra dos exércitos, não se pode atingir o fim estratégico, que é a destruição do inimigo e a ocupação de seu território, sem ter atingido antes uma série de objetivos táticos tendentes a desagregar o inimigo antes de enfrentá-lo em campo aberto (GRAMSCI, 2012, p. $544-545) \cdot{ }^{20}$

Ora, um desses objetivos táticos é, certamente, a formação cultural e política dos trabalhadores, por todos os meios possíveis, escolares ou não. No processo dessa formação, um primeiro aspecto a ser considerado é justamente o combate à concepção fatalista da história. É isso o que significa ter também cabeça e não apenas pulmões e garganta. Em outros termos, significa ação mediada pela reflexão e não imobilismo camuflado por uma "fraseologia ultra-esquerdista" (COUTINHO, 2007, p. 56), por um psitacismo panfletário, repetidor de slogans, de ideias e de palavras de ordem captadas mecânica e superficialmente, ao nível do senso comum, e que, pouco ou nada, contribuem para a formação das massas.

Para promover essa formação, as lideranças partidárias, isto é, aqueles que atuarão como educadores dos demais, devem se manter sempre em contato com os companheiros, ainda que por "correspondência epistolar" (GRAMSCI, 1973, p. 75) ${ }^{21}$. Por isso, "Onde quer que exista no exterior um grupo de dez companheiros, deve surgir uma escola de partido", na qual os membros "mais velhos e mais experientes devem ser os instrutores", a fim de "compartilhar com os mais jovens sua experiência" e, assim, "contribuir para elevar o nível político da massa" (Idem).

Evidentemente, Gramsci (1973, p. 75) tinha clareza de que "não é com esses meios pedagógicos que se resolverá o grande problema histórico da emancipação espiritual da classe operária". De fato, não era a "resolução utópica desse problema" que o grupo do L'Ordine Nuovo propunha. Os limites e o alcance da escola eram plenamente reconhecidos: destinava-se "ao partido", constituído de pessoas que, pelo simples fato de terem se filiado a ele, já demonstravam ter adquirido um "notável grau de emancipação espiritual". Portanto, o objetivo era a melhoria dos seus quadros com o intuito de "tornálos aptos a enfrentar as próximas lutas" (Idem). Em suma, tratava-se de "formar companheiros operários, capazes de um trabalho prático e não apenas de gritar 'Viva a revolução"” (Ibidem, p. 76).

Nosella (1992) menciona outros três textos de Gramsci, de 1925, importantes para o conhecimento dessa escola por correspondência. São eles: “A escola de partido”, publicado no L'Ordine Nuovo, em 1. ${ }^{\circ}$ de abril (GRAMSCI, 1973, p. 114-116); "Introdução ao primeiro curso da escola interna

\footnotetext{
${ }^{17}$ Manacorda (1990, p. 42) também menciona essa escola, assim como a anterior.

18 Tradução nossa.

19 A crítica gramsciana ao maximalismo se dirige, particularmente, ao líder comunista Amadeo Bordiga (COUTINHO, 2007, p. 35).

${ }^{20}$ Essa compreensão irá, mais tarde, ajudá-lo a elaborar o conceito de guerra de posição.

${ }^{21}$ A exigência de permanente contato dos intelectuais e da filosofia da práxis com as massas e os "simples", também será enfatizada nos Cadernos. Ver, por exemplo, Gramsci (2001, v. 1, C 10, \44, p. 398; C 11, \12, p. 103; \67, p. 221-222). 
do partido"22 (Idem, 1978, p. 50-57); e "A vida da escola" (Idem, p. 58-62). Os dois últimos correspondem também à introdução das duas únicas apostilas dessa escola, ambas preparadas por Gramsci.

$\mathrm{Na}$ condução de seu projeto político-educativo, Gramsci sabe que seria utópico esperar que toda a massa de operários e camponeses tivesse plena consciência do papel social e mundial de sua classe. Mas considera que isso deveria ser esperado, ao menos, dos membros do partido (GRAMSCI, 1978, p. 54). Sabe também que não seria possível modificar a consciência de toda a classe trabalhadora, antes da mudança no modo de vida dessa classe, isto é, sem que ela tivesse sob seu controle "o aparato de produção e de comércio e o poder estatal" (Idem). Afasta-se, assim, qualquer risco de atribuir a ele uma leitura idealista do papel da educação na construção do socialismo, o que, por outro lado, não implica, obviamente, negligenciar a luta política no campo ideológico. Muito pelo contrário, para ele é necessário que o partido "intensifique e torne sistemática a sua atividade" nesse campo (Ibidem, p. 55).

Justifica-se, portanto, a importância da formação dos militantes, pois o partido precisa viver e estar em contato com suas bases e, para isso, "é preciso que cada membro do partido seja um elemento político ativo, seja um dirigente" (GRAMSCI, 1978, p. 56). Em outras palavras, é preciso que o partido eduque seus integrantes e "eleve o seu nível ideológico", a tal ponto que, na eventual ausência dos dirigentes (por exemplo, por consequências de um regime autoritário),

todos os membros do partido, cada um em seu ambiente, estejam em condições de se orientar, de saber extrair da realidade os elementos para estabelecer uma direção, a fim de que a classe operária não se abata, mas sinta-se guiada e ainda em condições de lutar (GRAMSCI, 1978, p. 56).

Há, aqui, sem dúvida, uma preocupação em educar para a autonomia, inclusive dentro do partido. Para alcançar esse objetivo, o programa da escola por correspondência envolvia três blocos de lições: o primeiro sobre a "teoria do materialismo histórico"; o segundo, sobre "os elementos fundamentais de política geral"; e o terceiro sobre "o Partido Comunista e os princípios de organização que lhes são próprios" (GRAMSCI, 1978, p. 56).

Para o primeiro bloco, era indicado o livro de Bukharin sobre o materialismo histórico. ${ }^{23} \mathrm{O}$ segundo incluía os seguintes temas:

a economia política; o desenvolvimento do capitalismo até a época do capitalismo financeiro; a guerra e a crise do capitalismo; o desenvolvimento das formas econômicas; a sociedade comunista e o regime de transição; a doutrina comunista do Estado; a I e a II Internacional; a III Internacional; a história do Partido bolchevique russo; a história do Partido comunista italiano; o poder soviético e a estrutura da República dos Sovietes; a política econômica do poder dos Sovietes na época do comunismo de guerra; origem e base da nova política econômica; a indústria; a política agrária e a política campesina; comércio e cooperação; política financeira; os sindicatos, suas funções e suas tarefas; a questão nacional (GRAMSCI, 1978, p. 56).

Finalmente, o terceiro bloco destinava-se a estudar "sistematicamente a doutrina do partido e os princípios de organização revolucionária", de acordo com o estabelecido pela Internacional Comunista (GRAMSCI, 1978, p. 56-57).

Para dar suporte ao trabalho pedagógico, seriam publicadas, mensalmente, apostilas, abordando esses diversos temas, as quais deveriam ser estudadas, e não apenas lidas "como se lê um jornal ou um panfleto" (GRAMSCI, 1978, p. 57). E Gramsci acrescenta: "Os alunos devem estudar como

\footnotetext{
22 Segundo Einaudi (GRAMSCI, 1978, p. 50, nota 1), por algum tempo o texto "Introduzione al primo corso della scuola interna di partito" foi conhecido apenas tal como havia sido publicado em Stato operaio (Paris, março-abril de 1931, n. 3-4, p. 162-168), isto é, com o título de "Necessidade de uma preparação ideológica de massa" e sem os últimos seis parágrafos. Mais tarde, a descoberta no Arquivo do Partido Comunista Italiano, conservado pelo Instituto Gramsci, das duas primeiras e únicas apostilas da escola de partido por correspondência, editadas inteiramente por Gramsci, permitiu completar o artigo e concluir que ele constituía a introdução da primeira apostila lançada e difundida em abril-maio de 1925.

${ }^{23}$ Trata-se do Ensaio de Sociologia Popular, que, como assinala Nosella (1992, p. 61), Gramsci criticará posteriormente, no Caderno 11 (GRAMSCI, 2001, C 11, \$13, p. 114).
} 
se devessem passar em um exame de fim de curso, ou seja, devem se esforçar para recordar, para assimilar os assuntos tratados, de modo a serem capazes de fazer relações e pequenas exposições” (Idem).

$\mathrm{Na}$ elaboração das apostilas dever-se-ia levar em conta o "preparo médio das massas do partido". Poderia ocorrer que, para alguns, os assuntos já fossem conhecidos, enquanto, para outros, eram uma "novidade um pouco difícil de digerir". E, até certo ponto, era inevitável que isso ocorresse. Mas, nesse caso, os alunos deveriam se ajudar mutuamente, pois "a constituição de grupos e a repetição em comum das lições recebidas, podem às vezes eliminar esse obstáculo". Além disso, recomendava-se que escrevessem à direção da escola, se necessário, apresentando suas dificuldades, "solicitando maiores esclarecimentos e sugerindo outros métodos e outras formas de exposição" dos conteúdos (GRAMSCI, 1978, p. 57).

Concluído o primeiro bloco, Gramsci analisa as avaliações e os comentários que chegaram à direção do partido. Em relação às apostilas, a principal observação dizia respeito à forma "um tanto recortada e absoluta" da exposição do conteúdo, com assuntos "muito numerosos e vastos", de modo que seria necessário elaborar "um plano geral mais restrito" (GRAMSCI, 1978, p. 58).

Além disso, considerando o pouco preparo de boa parte dos alunos, havia o risco de que as apostilas fossem tomadas como "puro ouro", isto é, "verdade indiscutível", e eles acabassem memorizando mecanicamente aquilo que, em vez, deveria ser "objeto de discussão e exame" (GRAMSCI, 1978, p. 58). Gramsci reconhece esse risco e tem consciência de que o melhor tipo de escola é a presencial, "falada", e não aquela por correspondência:

$\mathrm{Na}$ escola falada, o professor tem diante de si os alunos, reunidos em um único local: conhece ou acaba por conhecer a todos individualmente; pode avaliar as capacidades e as limitações de cada um e pode elaborar um método e uma forma de exposição mais adequados para desenvolver as capacidades e superar as limitações; pode, vez por outra, corrigir falsas interpretações, esclarecer os equívocos, os mal-entendidos, as obscuridades, insistir em noções menos óbvias e mais complexas, procurar, em suma, fazer com que a escola viva coletivamente de modo que haja um desenvolvimento contínuo dos indivíduos e que esse desenvolvimento seja orgânico e sistemático (GRAMSCI, 1978, p. 58).

Evidentemente, o ensino a distância não oferecia essas condições. Os alunos que estudavam pelas apostilas eram "muitas centenas" e "muito diversos". Havia entre eles: "velhos e jovens"; "operários da cidade grande [...], onde o desenvolvimento do capitalismo fez surgir as formas econômicas e os fenômenos que são estudados nos cursos"; operários de cidades pequenas; "camponeses pobres", “empregados, estudantes, etc.” (GRAMSCI, 1978, p. 59). Em suma, havia pessoas

mais ou menos habituadas a refletir, mais ou menos pacientes diante das dificuldades, com maior ou menor experiência de vida vivida, mais ou menos capazes, portanto, de relacionar uma noção científica com os fatos reais e concretos que a iluminam e permitem compreender seu alcance e seu significado (GRAMSCI, 1978, p. 58-59).

Apesar dessa grande diversidade, "as lições deveriam ser as mesmas para todos, necessariamente" (GRAMSCI, 1978, p. 59), pois todos precisavam ser educados. E, como não seria possível oferecer um curso específico para cada um desses grupos, a saída era organizar as lições e os textos, levando-se em conta o "tipo médio de aluno" que, no entanto, "na realidade, só existe como abstração". Daí ser inevitável que as lições e as apostilas acabassem tendo um caráter "um pouco absoluto e abstrato, um pouco mecânico", que, certamente, não é o ideal nem o adequado para uma "escola proletária orgânica" (Idem).

Mas tampouco se pretendia "criar uma escola modelo, segundo os princípios da pedagogia e da didática", e sim "uma escola nas condições existentes", as quais eram "muito difíceis e árduas de dominar". De resto, nenhuma escola, por mais perfeita que seja, é suficiente para "educar e formar o indivíduo", pois "cada um se educa e se forma principalmente por si". A escola até "acelera essa formação", "ensina a estudar, habitua a uma disciplina intelectual", mas "não pode substituir o espírito de iniciativa no campo do saber" (GRAMSCI, 1978, p. 59). 
Além disso, era preciso considerar que a classe trabalhadora, "explorada e oprimida" materialmente, também "foi sistematicamente privada do saber científico". Para ela, o Estado burguês organizou um tipo de escola profissional, que visa a "manter a divisão das classes, a garantir que o filho do operário seja também um operário". Ora, dada essa organização classista da escola, que mantém o trabalhador sempre distante da ciência, a tendência é que ele nunca valorize o seu próprio conhecimento, mas, ao contrário, seja levado a subestimar-se. Na verdade,

o operário acredita sempre que é mais ignorante e mais incapaz do que realmente é; o operário experimenta sempre uma grande hesitação ao exprimir sua opinião, porque é persuadido de que sua opinião vale pouco, porque foi habituado a pensar que a sua função na vida não é a de produzir ideias, de dar a direção, de ter opinião, mas sim a de seguir as ideias dos outros, de executar a direção dos outros e escutar de boca aberta as opiniões dos outros (GRAMSCI, 1978, p. 60).

Não haveria, portanto, razão para tanta preocupação com o risco de que os alunos decorem mecanicamente o conteúdo das apostilas, ou mesmo de que se envaideçam por terem conseguido esse feito, pois isso pode, de algum modo, ajudar a elevar a sua autoconfiança e a sua autoestima. No entanto, sem dúvida, é um risco a ser "combatido sistematicamente" (GRAMSCI, 1978, p. 60).

Com o tempo, o sistema de contato com os alunos apenas por correspondência mostrou-se insuficiente. A escola crescera e já contava com mais de 600 estudantes, sendo impossível responder a todos. A saída seria a criação de um grupo de instrutores do partido (GRAMSCI, 1978, p. 61), os quais seriam escolhidos pelos próprios alunos de cada localidade, de acordo com os seguintes critérios: "boa vontade", "antiguidade de partido" e "relativa maior preparação, etc." (Idem). Caberia a esses instrutores "recolher os desejos dos alunos, responder eles mesmos às observações mais elementares" e "transmitir as demais à direção da escola, servindo assim de ligação entre o centro e a massa" (Idem). Além disso, deveriam atuar como "assistentes da escola": estudando as lições "não só para si, mas também para o grupo ao qual pertencem", a fim de se capacitarem para explicar as matérias aos demais (Idem).

Os temas abordados também deveriam sofrer adaptações, voltando-se mais diretamente para a realidade de cada grupo. Assim, "cada lição deve estar voltada para explicar praticamente os fenômenos que recaem sobre a experiência dos companheiros, seja no campo econômico, seja no político e ideológico" (GRAMSCI, 1978, p. 61). Esperava-se ainda que, dentre os instrutores, surgissem dirigentes capazes de "traduzir em linguagem compreensível às massas locais, as palavras de ordem do partido" (Idem).

\section{EDUCADOR NO CÁRCERE}

Em 8 de novembro de 1926, apesar da sua imunidade parlamentar, Gramsci foi preso pelo regime fascista. Após alguns dias de confinamento na prisão romana de Regina Coeli, juntamente com outros deputados comunistas, foi levado para a ilha de Ustica, onde permaneceria por cerca de dois meses, até ser transferido, em 4 de janeiro de 1927, para a prisão de San Vitore, em Milão.

Em Ústica, juntamente com outros prisioneiros, Gramsci organizou uma escola que era, ao mesmo tempo, elementar, de alfabetização, média e superior. Assim escreve ao amigo Piero Sraffa, ${ }^{24} \mathrm{em}$ carta de 21 de dezembro de 1926:

Em Ústica, somos trinta confinados políticos: já iniciamos toda uma série de cursos, básicos e de cultura geral, para os diversos grupos de confinados 25 ; também iniciaremos uma série de conferências. Bordiga dirige a parte científica, eu a parte histórico-literária; eis a razão pela qual

\footnotetext{
${ }^{24}$ Piero Sraffa (1898-1983) foi um prestigiado economista socialista, colaborador do L'Ordine Nuovo e membro do Partido Comunista Italiano. Desde a prisão de Gramsci, manteve correspondência epistolar com ele, comunicando-lhe notícias da família, em especial da esposa Giulia, que voltara à Rússia com os dois filhos do casal, e cumprindo a função de emissário do PCI. Sendo de família rica e influente, Sraffa pôde abrir uma conta para Gramsci na livraria Sperling \& Kupfer, de Milão, de onde lhe enviava os livros solicitados pelo amigo prisioneiro (HENRIQUES, 2005, p. 68-69).

${ }^{25}$ Segundo Henriques (2005, p. 101, nota 2), "os presos comuns não podiam frequentar os cursos nem ter qualquer outro contato com os confinados políticos".
} 
encomendei determinados livros. Esperamos, assim, passar o tempo sem nos embrutecermos e sendo úteis para os outros amigos, que representam toda a gama dos partidos e da preparação cultural. [...] Há três ou quatro analfabetos, ou quase; o restante tem uma preparação variada, mas com média muito baixa. Mas todos estão contentes por ter a escola, que é frequentada com grande assiduidade e aplicação (GRAMSCI, 2005a, p. 92-93).

Em outra carta, de 2 de janeiro de 1927, dá mais detalhes da escola ao amigo:

Já iniciamos uma escola, dividida em vários cursos: $1^{\circ}$ curso $\left(1^{\mathrm{a}}\right.$ e $2^{\mathrm{a}}$ séries primárias), $2^{\mathrm{o}}$ curso ( $3^{a}$ série primária), $3^{\circ}$ curso ( $4^{a}$ e $5^{a}$ séries primárias), curso complementar, dois cursos de francês (básico e avançado), um curso de alemão. Os cursos são estabelecidos em função do conhecimento nas matérias que podem ser reduzidas a um certo conjunto de noções exatamente determináveis (gramática e matemática); por isso os alunos dos cursos primários frequentam as lições de história e geografia do curso complementar, por exemplo. Em resumo, tentamos combinar a necessidade de uma seriação escolar com o fato de que os alunos, embora às vezes semianalfabetos, são intelectualmente desenvolvidos. Os cursos são seguidos com grande esmero e atenção. Com a escola, que também é frequentada por alguns funcionários e habitantes da ilha, evitamos os perigos do desânimo, que são imensos. Você nem pode imaginar as condições de embrutecimento físico e moral a que foram reduzidos os presos comuns (GRAMSCI, 2005a, p. 99-100).

Escrevendo à cunhada Tatiana, em 3 de janeiro de 1927, Gramsci conta que se encarregava do ensino de história e de geografia e que frequentava o curso de alemão. Era, portanto, professor e aluno na "escola de cultura geral" dos confinados (GRAMSCI, 2005a, p. 102).

Transferido para a prisão de Milão, Gramsci foi obrigado a interromper essa atividade docente e discente. Contudo, a escola de cultura continuou a funcionar em Ústica e ele passou a orientar por correspondência os companheiros que lá permaneceram. ${ }^{26}$ Foi o caso de Giuseppe Berti, por exemplo, a quem escreveu em 4 de julho de 1927. Apesar de se encontrar em um momento de extremo "cansaço moral", provocado por acontecimentos familiares, "muito nervoso e irascível" e com dificuldade para se concentrar em qualquer assunto, não se furtou a responder ao antigo colega de cárcere que lhe pedira conselhos e "ideias 'geniais" sobre a condução das atividades escolares. Sua resposta:

A meu ver, uma das atividades mais importantes a serem desenvolvidas pelo corpo docente seria registrar, desenvolver e coordenar as experiências e as observações pedagógicas e didáticas; só desse trabalho contínuo pode nascer o tipo de escola e o tipo de professor que o ambiente requer. Que belo livro se poderia fazer sobre essas experiências, e como seria útil! (GRAMSCI, 2005a, p. 167)

Quanto às ideias geniais, para o desapontamento do destinatário, responde: "Penso que a genialidade deve ser 'enterrada' e, ao contrário, deve ser aplicado o método das experiências mais minuciosas e da autocrítica mais desapaixonada ou objetiva” (GRAMSCI, 2005a, p. 167). Recusa-se, portanto, a dar receitas e, em vez disso, convida à reflexão crítica sobre a prática pedagógica. Porém, não deixa de incentivar moralmente o colega, expressando confiança em sua capacidade para enfrentar as dificuldades. A respeito da organização da escola, recomenda a Berti:

Assim por alto, penso que a escola deveria ter três graus (fundamentais, porque cada grau poderia ser dividido em cursos): o terceiro grau deve ser o dos professores ou equivalentes e funcionar mais como círculo do que como escola em sentido comum. Ou seja, cada componente deve dar sua contribuição como conferencista ou relator de determinados temas científicos, históricos ou filosóficos, mas especialmente didáticos e pedagógicos (GRAMSCI, 2005a, p. 167).

Podemos notar claramente a preocupação de Gramsci com a formação, sobretudo didática e pedagógica, dos professores e com a forma como ela deveria se realizar: pelo estudo coletivo,

${ }^{26}$ A esse respeito, ver também Nosella (1992, p. 71).

Educação em Revista|Belo Horizonte|v.37|e20049|2021 
compartilhado, interdisciplinar, visando à ampliação do conhecimento de todos sobre a área de domínio de cada um. ${ }^{27}$

\section{CONSIDERAÇÕES FINAIS}

Muitos outros textos de Gramsci precisariam ser estudados para caracterizar com precisão sua prática pedagógica e identificar os princípios e os pressupostos teóricos em que ela se fundamenta. Creio, porém, que o caminho percorrido até aqui foi suficiente para demonstrar seu compromisso radical com a formação das camadas populares, tendo em vista sua capacitação intelectual e moral para compreender criticamente a realidade em que vivem e agir com autonomia para transformá-la. Cabe, agora, retomar sinteticamente alguns dos aspectos dessa prática, extraídos das fontes aqui examinadas, e que poderiam ser constitutivos de sua pedagogia.

Inicialmente, importa destacar seu reconhecimento da importância da escola para a classe trabalhadora, apesar do caráter discriminatório dessa instituição na sociedade capitalista. Sem ela, porém, essa classe estaria em ainda maior desvantagem em relação à burguesia. Daí a necessidade de exigir que a escola seja séria e capaz de ensinar também aos operários o saber que tem sido privilégio das elites econômicas.

Mas uma educação destinada às massas populares não pode descuidar da linguagem empregada no processo de ensino, a qual deve evitar os extremos do academicismo pedante e da facilitação populista. Ambos impedem o acesso das pessoas simples ao saber: o primeiro, por torná-lo hermético e incompreensível; o segundo, por empobrecê-lo, convertendo-o em discurso panfletário, em catecismo doutrinário. Há que adaptá-la, portanto, ao nível médio dos estudantes, mas elevando-a um pouco acima dessa média, a fim de possibilitar o crescimento intelectual e cultural de todos. E isso vale tanto para a linguagem oral, adotada nas aulas e nas conferências, quanto para a linguagem escrita, dos textos selecionados e dos materiais didáticos.

O mesmo princípio metodológico da elevação cultural das massas se aplica na seleção dos conteúdos. Gramsci almeja para os trabalhadores uma educação integral, omnilateral, que abranja todos os campos do saber e rompa com a tradição burguesa de reservar a eles o ensino profissionalizante ou uma formação escolar aligeirada, insossa, insignificante e inofensiva. Mesmo a educação extraescolar, realizada no e pelo partido, deve seguir esse princípio. Do contrário, os alunos não poderão se tornar pessoas autônomas, capazes de "pensar, de estudar, de dirigir ou de controlar quem dirige" (GRAMSCI, 2006, C 12, \$2, p. 49). Trata-se, na realidade, de uma concepção radicalmente democrática da educação, na medida em que almeja “transformar cada 'cidadão' em 'governante' [assegurando-lhe] o aprendizado gratuito das capacidades e da preparação técnica geral necessárias a essa finalidade” (GRAMSCI, 2006, C $12, \$ 2$, p. 50$)$.

Não se trata, porém, vale lembrar, da cultura em sentido enciclopédico, típica da prática pedagógica bancária, descrita e criticada por Paulo Freire e que serve mais para criar pessoas arrogantes e pernósticas e discriminar ainda mais as simples. Cultura, para Gramsci, é conhecer-se a si mesmo, reconhecer o próprio valor histórico e social e os próprios direitos e deveres; ser capaz de refletir com inteligência sobre os problemas concretos; ter consciência de classe. Significa, ainda, elaborar criticamente a própria concepção do mundo, agir como sujeito da história; guiar-se a si próprio e deixar de aceitar passivamente as influências externas sobre a própria maneira de pensar, agir e sentir.

A aquisição dessa cultura não ocorre espontaneamente, mas, antes, requer uma ação educativa intencional, tarefa que compete aos intelectuais e, em especial, aos educadores, seja atuando na escola, seja em quaisquer outros espaços educativos. Requer também métodos adequados de ensino, que favoreçam especificamente essa formação cultural. Ora, todo método, para ser eficiente, precisa partir das condições reais em que se atua, levar em conta as especificidades do público a ser atingido. E, em se tratando de uma educação voltada para as camadas populares que, via de regra, têm menos familiaridade com a chamada "cultura escolar", cumpre cuidar para que os conteúdos sejam abordados didaticamente, o que supõe, entre outras medidas: apresentá-los com clareza e em linguagem adequada, como já foi

\footnotetext{
${ }^{27}$ Essa recomendação do trabalho coletivo nos remete à proposta dos círculos de cultura que será apresentada nos Cadernos. Ver Gramsci (2006, C12, \$1, p. 35).
} 
salientado; articulá-los com a experiência dos alunos, para que ganhem sentido concreto para eles e os motivem a estudar e a participar das aulas; apontar, de cada assunto, os tópicos principais e os que mereçam mais atenção; explicitar o raciocínio desenvolvido pelos autores dos textos utilizados, para que os alunos aprendam a reconhecer seus nexos lógicos e aprimorem sua própria capacidade de pensar e de se expressar oralmente e por escrito; apresentar um resumo curto de cada lição, que sintetize esses tópicos; indicar bibliografia complementar para aqueles que desejarem e puderem se aprofundar no estudo; promover a discussão por todo o grupo, em clima de liberdade e respeito, sobre as questões levantadas; solicitar aos alunos que exponham oralmente e por escrito os temas estudados; propor exercícios que permitam a eles elaborar sua própria compreensão desses temas; avaliar criteriosamente a aprendizagem.

Merece destaque também a importância dada por Gramsci ao trabalho coletivo, por meio do qual os mais avançados auxiliam os que têm mais dificuldades, de modo que todos aprendam e se enriqueçam culturalmente uns com os outros. Além dos benefícios propriamente pedagógicos, a experiência de cooperação mútua, propiciada por essa estratégia metodológica, pode: fortalecer os laços afetivos e de companheirismo entre os colegas, o que é fundamental também para sua organização como classe; estimular o surgimento de lideranças naturalmente legitimadas pelo grupo; e, ainda, auxiliar na superação de problemas de inibição e de baixa autoestima.

Ainda sobre a questão metodológica, Gramsci recomenda a adoção do método historicista que, em lugar de expor dogmaticamente o conteúdo, refaz com os alunos o percurso do pesquisador estudado, mostrando seus erros e acertos, para que se apropriem não apenas do resultado da pesquisa, mas também do método nela empregado.

Quanto ao material didático, também deve ser adaptado à realidade dos alunos, o que vale tanto para a linguagem usada, quanto para a extensão dos textos e o grau de complexidade dos assuntos incluídos. E realizar essa adaptação é responsabilidade do educador, mesmo que ele próprio precise elaborar e reelaborar esse material.

É importante, também, que os professores registrem e avaliem desapaixonada e continuamente sua prática e se disponham a alterá-la em função das necessidades detectadas. No fundo, essa disposição para a autocrítica e para a mudança de rumo resulta do reconhecimento de que o plano de ensino se subordina às condições objetivas, e não o contrário, sob pena de que, ao orientar-se por uma concepção idealista, ampliem-se consideravelmente os riscos de insucesso.

A respeito da educação a distância, talvez possamos aprender com Gramsci a dimensionar seu valor mais equilibradamente e tomá-la como uma alternativa excepcional ou complementar, que não pode substituir a experiência viva do contato direto professor-aluno, mas que, em circunstâncias particulares, tampouco pode ser descartada. Nesse sentido, o advento da internet e o desenvolvimento de sofisticadas plataformas educacionais representam um potencial gigantesco a ser explorado critica e criativamente na educação das massas. Abdicar a priori desse recurso pode ser um equívoco político de consequências significativas.

Finalmente, é importante mencionar um aspecto que atravessa todos os demais supracitados e, na verdade, toda a vida de Gramsci: seu radical compromisso ético e político com a educação, em especial com a das camadas populares. Marx (1991, p. 117) havia afirmado: "as armas da crítica não podem, de fato, substituir a crítica das armas; a força material tem de ser deposta por força material, mas a teoria também se converte em força material uma vez que se apossa dos homens". Ora, talvez nenhum outro pensador e militante marxista tenha incorporado tão organicamente essas palavras e conseguido traduzi-las em uma ação pedagógica tão plena e continuamente assumida. E isso apesar de todas as enormes adversidades que teve de enfrentar ao longo da vida: saúde sempre frágil, condições econômicas precárias, perseguição política, clandestinidade, encarceramento arbitrário, violência física e moral, apartamento da família e dos amigos, privação das condições mínimas de dignidade. Nada disso, porém, abalou a sua força vital, nem o impediu de encontrar os meios e as formas adequadas, em cada circunstância, para prosseguir. Guardadas as devidas proporções, a realidade brasileira atual, com traços nítidos de neofascismo e de obscurantismo, também se faz sombria, assustadora, ameaçadora e impõe inúmeras dificuldades aos que se comprometem com a educação dos subalternizados. No entanto, olhando para a trajetória de Gramsci, podemos encontrar nela uma fonte de inspiração e de coragem para um engajamento também radical nessa tarefa e para empreendê-la por todos os meios, de todas as 
formas e em todos os espaços possíveis. Embora esse seja um trabalho de longo prazo, talvez seja o caminho mais curto - no terreno da educação - para, enfim, celebrarmos a conquista do reino da liberdade e a ele brindarmos, todos, metafórica e literalmente, com vinho Barolo.

\section{REFERÊNCIAS}

COUTINHO, Carlos N. Gramsci: um estudo sobre seu pensamento político. 3. ed. Rio de Janeiro: Civilização Brasileira, 2007.

D’ORSI, Angelo. Gramsci: Uma nuova biografia. Firenze: Universale Economica Feltrinelli; Storia, 2018

FREIRE, Paulo. Pedagogia do oprimido. Rio de Janeiro: Paz e Terra, 2016.

GRAMSCI, Antonio. Cronache del 'L'Ordine Nuovo'. L’Ordine Nuovo, a. 1, v. 31, 20, p. 1, dez. 1919 a. Disponível em: www.centrogramsci.it/riviste/nuovo/ordine $\% 20$ nuovo $\% 20$ p3.pdf. Acesso em: 3 nov. 2019.

GRAMSCI, Antonio. Cronache del 'L'Ordine Nuovo'. L'Ordine Nuovo, a. 1, v. 30, n. 27, p. 1, dez. 1919b. Disponível em: www.centrogramsci.it/riviste/nuovo/ordine $\% 20$ nuovo\%20p3.pdf. Acesso em: 3 nov. 2019.

GRAMSCI, Antonio. Il programa della scuola di propaganda. L’Ordine Nuovo, a. 1, n. 28, p. 2, 29 nov. 1919c.

GRAMSCI, Antonio. La Scuola di propaganda a Torino. L'Avanguardia, Giornale della Gioventù Socialista Italiana, Roma, a. 13, n. 614, 14 dez. 1919d.

GRAMSCI, Antonio. Massimalismo ed extremismo. L’Unità, a. 2, n. 151, 2 jul. 1925. Disponível em: https://paginerosse.wordpress.com/2012/04/14/a-gramsci-massimalismo-ed-estremismo-2/. Acesso em: 30 out. 2019.

GRAMSCI, Antonio. L’ordine Nuovo: 1919-1920. Torino: Giulio Einaudi Editore, 1955.

GRAMSCI, Antonio. Scritti politici III. Org. Paolo Spriano. v. III. Roma: Editori Riuniti, 1973.

GRAMSCI, Antonio. La costruzione del partito comunista 1923-1926. 5. ed. Org. Giulio Einaudi. Torino: Giulio Einaudi Editore, 1978.

GRAMSCI, Antonio. Vita attraverso le lettere. Org. Giuseppe Fiori. Torino: Giulio Einaudi Editore, 1994.

GRAMSCI, Antonio. Cadernos do Cárcere. Ed. Carlos Nelson Coutinho, Marco Aurélio Nogueira e Luiz Sérgio Henriques. Trad. Carlos Nelson Coutinho. v. 1. Rio de Janeiro: Civilização Brasileira, 2001.

GRAMSCI, Antonio. Cartas do Cárcere. v. 1. 1926-1930. Org. Carlos Nelson Coutinho e Luiz Sérgio Henriques. Trad. Luiz Sérgio Henriques. Rio de Janeiro: Civilização Brasileira, 2005a.

GRAMSCI, Antonio. Cartas do Cárcere. v. 2. 1931-1937. Org. Carlos Nelson Coutinho e Luiz Sérgio Henriques. Trad. Luiz Sérgio Henriques. Rio de Janeiro: Civilização Brasileira, 2005b. 
GRAMSCI, Antonio. Cadernos do Cárcere. v. 2. Ed. Carlos Nelson Coutinho, Marco Aurélio Nogueira e Luiz Sérgio Henriques. Trad. Carlos Nelson Coutinho. Rio de Janeiro: Civilização Brasileira, 2006.

GRAMSCI, Antonio. Scritti dalla libertà (1910-1926). Org. Angelo d'Orsi e Francesca Chiarotto. Roma: Editori Internazionali Riuniti, 2012.

HENRIQUES, Luiz Sérgio. Introdução. In: GRAMSCI, A. Cartas do Cárcere. v. 1. 1926-1930. Org. Carlos Nelson Coutinho e Luiz Sérgio Henriques. Trad. Luiz Sérgio Henrique. Rio de Janeiro: Civilização Brasileira, 2005. p. 7-59.

KENNY, Anthony. Uma nova história da filosofia ocidental. v. II Filosofia Medieval. Trad. Edson Luiz Macedo Bini. Rev. Téc. Marcelo Perinie. São Paulo: Loyola, 2008.

MAESTRI, Mario; CANDREVA, Luigi. Antonio Gramsci: vida e obra de um comunista revolucionário. São Paulo: Expressão Popular, 2001.

MANACORDA, Mario A. O princípio educativo em Gramsci. Trad. William Lagos. Sup. e rev. téc. Tomaz Tadeu da Silva. Porto Alegre: Artes Médicas, 1990.

MARX, Karl. Introdução à crítica da filosofia do direito de Hegel. In: MARX, Karl. A questão judaica. 2. ed. São Paulo: Editora Moraes Ltda., 1991.

MORAES, Dênis de. Antonio Gramsci e o jornalismo. Carta Maior, 24 ago. 2014. Disponível em: www.cartamaior.com.br/?/Editoria/Midia/-Antonio-Gramsci-e-o-jornalismo\%20/12/31665. Acesso em: 26 out. 2019.

MUSSI, Daniela; BIANCHI, Alvaro. Antonio Gramsci, a cultura socialista e a revolução russa. Lua Nova: Revista de Cultura e Política, São Paulo, n. 102, p. 267-299, set./dez. 2017. Disponível em: www.scielo.br/scielo.php?script=sci_arttext\&pid=S0102-64452017000300267. Acesso em: 26 out. 2019.

NOSELLA, Paolo. A escola e Gramsci. Porto Alegre: Artes Médicas, 1992.

NOSELLA, Paolo. Formação escolar de Gramsci: escolha da profissão (Sardenha e Turim, 1891-1915). Novos Rumos - Unesp, Marília, v. 54, n. 2, p. 1-28, 2017. Disponível em: http://webcache.googleusercontent.com/search?q=cache:KjqJXW6CX6MJ:www.bjis.unesp.br/revista s/index.php/novosrumos/article/download/8532/5469/ \&cd=1\&hl=pt-

BR\&ct $=$ clnk\&gl=br\&client $=$ safari. Acesso em: 5 nov. 2019.

PIO, Thaís Pereira B. Silva. O discurso sobre a terra italiana nas Geórgicas de Virgílio. Codex - Revista de Estudos Clássicos, Rio de Janeiro, v. 5, n. 2, p. 137-154, jul./dez. 2017. Disponível em: https://revistas.ufri.br/index.php/CODEX/article/view/13467/9862. Acesso em: 5 nov. 2019.

SILVEIRA, Renê José Trentin. A Relação Professor-Aluno de uma Perspectiva Gramsciana. Educação \& Realidade, Porto Alegre, v. 43, n. 1, p. 97-114, jan./mar. 2018. Disponível em: www.scielo.br/scielo.php?script=sci arttext\&pid=S2175-62362018000100097. Acesso em: 15 out. 2020.

STATUTO Fondamentale della Monarchia di Savoia, 4 de março de 1848. Disponível em: https://storia.camera.it/img-repo/statuto albertino.pdf. Acesso em: 10 dez. 2019. 
Aprovado: 03/11/2020 